\title{
Mandela y la construcción histórica de la noviolencia - Otras formas de hacer y de pensar
}

\section{Carlos Eduardo Martínez Hincapié}

Uniminuto, Bogotá, Colombia.

Email: cmartinez_esp@yahoo.com

\begin{abstract}
Resumen: La propuesta de la noviolencia es una construcción histórica, es decir, hija de los retos que como humanidad hemos tenido en los últimos cien años. Es también una propuesta de transformación cultural que pretende dar cuenta de cambios profundos en nuestras formas de relacionarnos entre los humanos y con la naturaleza. Este escrito parte por poner sobre la mesa algunos imaginarios que aún guían la forma de hacer política, para evidenciar que necesitamos acudir a nuevas epistemologías, que se condensan en esta propuesta, y que nos permitan afinar nuestras percepciones de los cambios que se están dando. Mandela y su gente hicieron de la política el arte del encuentro y no de la confrontación. Se trata de evidenciar varios de los elementos que les permitieron salir avante de la tentación de la guerra y leerlos como su aporte a este camino en proceso, que es la noviolencia.

Palabras claves: cultura, hegemonía, micropolítica, macropolítica, líneas de fuga, noviolencia.
\end{abstract}

\section{Mandela and the historic construction of nonviolence- Other ways of doing and thinking}

\begin{abstract}
The proposal of nonviolence is an historical construction, meaning that it is the product of the challenges that we have faced as mankind in the last onehundred years. It is also a proposal for cultural transformation that intends to explain the deep changes in the ways of interacting among humans and with nature. This article starts placing the imaginaries that still guide the way of doing politics. Thus, we can evidence the need to reach out to new epistemologies that will allow us to tune our perceptions on the changes that are happening. Mandela and his people turned politics into the art of meeting and understanding and not that of confrontation. This text is about evidencing some of the elements that allowed them to overcome the temptation of war and to read them as their contribution to this pathway that is being built currently as a process, which is nonviolence. nonviolence.

Key words: culture, hegemony, micropolitics, macropolitics, outflow lines,
\end{abstract}

\section{Mandela e a construção histórica da não-violência - Outras formas de fazer e pensar}

Resumo: A proposta da não-violênciaé uma construção históriça, isto é, filha dos desafios que como humanidade ti vemos nos últimos cemanos. É também 
uma proposta de transformação cultural que procura explicar as mudanças profundas em nossas formas de relacionamento entre seres humanos e natureza. Este trabalho parte por colocar sobre a mesa alguns imaginários que ainda orientam a forma de fazer política, para mostrar que precisamos de novas epistemologias, que se condensam na presente proposta e que permitem-nos aguçarnos sãs percepção das mudanças que estão ocorrendo. Mandela e seupovo fizeramda políticaa arte do encontro e não da confrontação. É evidente que vários dos elementos que lhes permitiram chegar à frente da tentação de guerra e lê-loscomo o seu contributo para este caminho em processo, é efetivamente a não-violência.

Palavras-chave: cultura, hegemonia, micropolítica, macropolítica, linhas de fuga, não-violência.

\section{Introducción}

Vivimos en un mundo de profundos cambios. Los ropajes culturales que han acompañado nuestra existencia colectiva ya no logran comprender los nuevos retos que nos está planteando la vida. Sin embargo, seguimos aferrados a ellos por el miedo a la incertidumbre, aunque su utilización sistemática dé cuenta de su incapacidad para romper el círculo vicioso de todo tipo de violencias, que no solo se expresan y evidencian entre los seres humanos, sino que también rompen los equilibrios naturales que nos sustentan.

Es en el contexto de la capacidad de destrucción evidenciada en las guerras mundiales, de las profundas crisis ecológicas, del dolor multiplicado, que empieza a emerger la propuesta de la noviolencia, como pequeños brotes en el campo que sólo es posible percibirlos si nos acercamos cuidadosamente a ellos, o si tomamos la suficiente distancia como para evidenciar que la tierra seca empieza a vestirse de un verdor todavía tímido. Éste es el ejercicio que quiero hacer en este ensayo académico, asumiendo el reto de romper sus propios límites, pues solo así es posible ver más allá de la evidencia y captar aquello que la cultura hegemónica impide o dificulta. Es una emergencia que se está construyendo con el aporte, no necesariamente consciente, de mujeres yhombres en todas las latitudes del planeta y en el ámbito tanto de la macro como de la micropolítica, deshaciendo este dualismo espacio/temporal. Me referiré especialmente a algunos de los aportes de Mandelaa este propósito de humanidad, como paradigma de un proceso necesariamente colectivo, que procuró fugarse del círculo vicioso de las violencias. No pretendo con ello definir sus límites, sino mostrar formas de fuga que nos pueden sugerir adentrarnos en caminos sin hacer o poco explorados.

Parto por evidenciar las rutas recorridas en las que seguimos empeñados, aunque sólo consigamos la multiplicación exponencial de los problemas que pretendemos solucionar. Empezaré por mostrar algunos de los patrones que guían e inspiran la reflexión de la política y lo político para acercarme a nuevas epistemologías que dan cuenta de hechos históricos 
que por ser aparentemente excepcionales o no responder a lo que se espera desde la forma hegemónica de percibir la realidad, terminamos creyendo que no existen o que son exotismos históricos sin posibilidad de ser replicados. Casi que hemos terminado aceptando que esta realidad, que no es otra cosa que construcciones históricas y sociales, se haya instalado como una impronta natural de la que no podemos eximirnos como sociedad humana. También son una evidencia de lo poco que han cambiado los imaginarios atávicos ${ }^{1}$ que dan sentido y significación a nuestros actos.

\section{El poder, la política y la cultura}

Hemos expuesto en otro lugar que la cultura es una especie de cuenco o vasija cuyas formas están definidas por sus propios límites, determinados por los imaginarios atávicos y construidos en momentos de la historia de colectivos humanos concretos. El cuenco cultural, como realidad delimitada y universo cerrado de significaciones, nos brinda la seguridad que necesitamos, porque sus formas han sido definidas desde verdades que han demostrado sus capacidad para proteger la vida, y salirse de él puede suponer situarse al borde del abismo de la incertidumbre. (Martínez 2014: 15).

Lo que impresiona no es que Hobbes siga siendo el inspirador de la teoría política del Estado, ni que Schmitt continúe teniendo razón en su análisis sobre la relación amigo-enemigo, como sustento de toda relación política; lo que realmente llama la atención es que sus escritos siguen dando cuenta del acontecer político, a pesar de la "cantidad de agua que ha corrido debajo del puente" desde entonces.

La reflexión de Thomas Hobbes parte de un equívoco: atribuir a la naturaleza aprendizajes colectivos establecidos a través de la cultura. Las consecuencias de ello son definitivas, pues de ser lo primero, sólo se puede sugerir la represión, mientras que de entenderlo como aprendizajes la alternativa pasa por transformarlas. Hace parte de nuestro condicionamiento natural la necesidad de crear cultura para sobrevivir como especie, pero las características concretas de la misma son cambiantes, son históricas y son sociales. La competencia, la desconfianza y la gloria, que Hobbes atribuye a la naturaleza del hombre y como las causas de la discordia (Hobbes, 1651: 52), responden directamente al imaginario atávico del predominio de los más fuertes. Esto es consecuencia, más que de la naturaleza humana, de una cultura naturalizada, que tiene como una de sus fuentes este imaginario atávico de la supremacía de los más fuertes, que supedita al colectivo y delega en ellos el poder de cada cual. Dicha supremacía ha tenido diferentes expresiones: en principio fue la dominación desde la fuerza física, en otros momentos de la historia ha sido fortaleza política, militar o económica, cuando no la combinación de varias de ellas. Ha cambiado el sujeto de la fuerza, pero no la supeditación que ella imprime.

Históricamente, el Estado termina siendo la institucionalización de las sociedades patriarcales. Hemos creído avanzar políticamente cambian- 
do el soberano a través de elecciones, pero sus características siguen siendo las mismas. A él le seguimos atribuyendo una especie de sabiduría infusa que lo hace superior al resto de los mortales, delegando el poder de cada cual en aras de una protección que no es otra cosa que una creencia.

Hobbes señala en 1651 que "el fin del Estado es, particularmente, la seguridad. La causa final, fin o designio de los hombres (que naturalmente aman la libertad y el dominio sobre los demás) al introducir esta restricción sobre sí mismos (en la que los vemos vivir formando Estados) es el cuidado de su propia conservación y, por añadidura, el logro de una vida más armónica; es decir, el deseo de abandonar esa miserable condición de guerra que, tal como hemos manifestado, es consecuencia necesaria de las pasiones naturales de los hombres, cuando no existe poder visible que los tenga a raya y los sujete, por temor al castigo... Los pactos que no descansan en la espada no son más que palabras, sin fuerza para proteger al hombre, en modo alguno". (Ibid: 70).

Es el miedo al otro lo que conduce a esta delegación, haciendo del temor el instrumento de regulación social por excelencia y otro de los imaginarios de la cultura que nos hegemoniza. Este mecanismo se reproduce en todas las esferas de la vida social, pequeños hologramas que garantizan la supeditación. En la familia, es el padre o su representación el que impone la delegación de la autonomía a cambio de la protección. En las instituciones escolares, el profesor ejerce las mismas funciones y así quien detenta el poder puede, incluso, ponerse por fuera de la ley que pretende regularlo, si eso se requiere para construir esa apariencia de bienestar en todos y todas ${ }^{2}$.

La representación, entonces, no está sustentada por el acuerdo colectivo, sino por la esencia del representante. A pesar de los avances conceptuales de la forma de gobierno llamada democracia, en la realidad las personas otorgan a sus gobernantes una especie de bondad infusa o consentimiento, que les impide cuestionarlos en profundidad. Casi que sin ellos y por fuera de ellos solo queda la anarquía y el caos, lo que Hobbes llama la condición de guerra.

Lo que no devela este autor es que el miedo rompe la posibilidad de construir las confianzas necesarias para encontrar alternativas reales a dicha condición de guerra. El imaginario del miedo, como regulador social, es una de las fuentes de la guerra y no puede ser su solución; sin embargo, frente al terrorismo como arma de socialización del sufrimiento, se responde con medidas de fuerza que extienden tal sufrimiento a sectores ajenos a la lucha, considerándolas "daños colaterales", lo que demuestra lo actuales que son los planteamientos hobbesianos. El miedo impone la fuerza necesaria para que el opositor sienta más miedo que el que produce y los propios se sientan seguros. No hemos avanzado demasiado desde el siglo XVII. Siguiendo al mismo autor:

"Esta es la generación de aquel gran LEVIATÁN, o más bien (hablando con más reverencia), de aquel dios mortal, al cual debemos, bajo el 
Dios inmortal, nuestra paz y nuestra defensa. Porque en virtud de esta autoridad que se le confiere por cada hombre particular en el Estado, posee y utiliza tanto poder y fortaleza, que por el terror que inspira es capaz de conformar las voluntades de todos ellos para la paz, en su propio país, y para la mutua ayuda contra sus enemigos, en el extranjero”. (Ibid: 72).

El miedo al otro solo consigue la ruptura de la solidaridad y de su capacidad para garantizar la continuidad de la vida; ella fue fundamental en muchas ocasiones de nuestra historia humana y garante de la continuidad de la vida en momentos en que la misma se vio amenazada, como lo evidencian cada vez más los estudios desde la paz.

La naturalización del estado de guerra, que plantea Hobbes, es lo que sigue justificando todo tipo de guerras que esté en el marco de la dominación de los más fuertes. Igual reacción, desde los más frágiles, es considerada terrorismo. Produce más indignación social que un hijo maltrate a sus padres, que la violencia de los adultos contra los niños y las niñas que, para la mayoría de la gente, es educación. Está legitimada, y en muchos casos legalizada, la violencia de los fuertes contra los frágiles. De hecho, ni siquiera es percibida como tal.

"De la desconfianza, la guerra. Dada esta situación de desconfianza mutua, ningún procedimiento tan razonable existe para que un hombre se proteja a sí mismo, como la anticipación, es decir, el dominar por medio de la fuerza o por la astucia a todos los hombres que pueda, durante el tiempo preciso, hasta que ningún otro poder sea capaz de amenazarle”. (Ibid: 51)

Este miedo al otro ha construido sociedades monocromáticas que someten o expulsan las diferencias. El objetivo del pluralismo solo es un buen título que esconde la incapacidad que tienen las sociedades humanas de convivir con el diferente, que sólo es admitido si es capaz de demostrar que asume las costumbres mayoritarias, es decir, si deja de ser quien es, en abierta contradicción con lo que plantean los ecosistemas que sobreviven y se fortalecen gracias a la diversidad.

Tres siglos después, Carl Schmitt le aporta nuevos desarrollos a los planteamientos de Hobbes, al centrar el concepto de lo político en la relación amigo-enemigo, que hace referencia al imaginario atávico de la comprensión de la realidad a través de dualismos.

La esencia de los dualismos está en percibir dicha realidad como una lucha constante de opuestos irreconciliables y definidos desde la ausencia absoluta de elementos comunes. Es así como el conflicto surgido sólo es posible solucionarlo a partir de la dominación o la destrucción del polo opuesto, por eso todo dualismo tiende al unanimismo. La relación dualista amigo-enemigo termina legitimando el imperio de los más fuertes, a los que se equipara con los más buenos, los más capaces, en resumen, la medida de lo ético y lo estético. 
El miedo al otro, planteado por Hobbes, se manifiesta como el enemigo en Schmitt.

"El enemigo político... Es simplemente el otro, el extraño, y le basta a su esencia el constituir algo distinto y diferente en un sentido existencial especialmente intenso de modo tal que, en un caso extremo, los conflictos con él se tornan posibles”. (Schmitt, 1932: 13).

Schmitt intenta restringir esta relación dualista al campo de lo político, desconociendo que la percepción dualista y excluyente es una característica cultural, que se aplica a todos los ámbitos de la vida social. En este sentido, el agrupamiento amigo-enemigo se configura de forma permanente, así como la consecuente lógica de la guerra, entendida no solo como un enfrentamiento armado, sino como una manera de excluir, dominar o eliminar a través de la violencia, ya sea cultural, estructural o directa, a quien se presenta como un no amigo, como un "diferente en un sentido existencial intenso", para usar sus propias palabras.

De nuevo se presenta el problema de identificar un aprendizaje cultural como una condición insoslayable. Creer que las diferencias sólo se pueden tramitar a través de la concepción amigo-enemigo significa seguir condenando a la humanidad a recorrer sistemáticamente el camino de la guerra, a entender la paz como el triunfo de la dominación y a ejercer la política como un campo de batalla, como lo dice Schmitt.

"Un mundo en el cual la posibilidad de un combate estuviese totalmente eliminada y desterrada, una globo terráqueo definitivamente pacificado sería un mundo sin la diferenciación de amigos y enemigos y, por lo tanto, sería un mundo sin política... La guerra, en tanto medio político más extremo, revela la posibilidad de esta diferenciación entre amigos y enemigos, subyacente a toda concepción política” (Ibid: 18).

Este autor intenta separar el "sentido de lo político" de diferenciaciones de tipo moral, estético, ético o económico, para dejar la categoría amigo-enemigo en el campo exclusivo de la política; sin embargo, en la práctica el concepto de enemigo necesita de apreciaciones morales, necesita ser equiparado con el mal para ser comprendido como tal; necesita de la competencia para poder justificar el medir fuerzas que destruyan o sometan al que encarna intereses opuestos; se requiere que sea equiparado con lo grotesco, con lo inconveniente, de forma que se legitime el uso de la fuerza necesaria para su destrucción. Incluso se animaliza al enemigo, como una forma de justificar su dominación, de quitarle la posibilidad de ser mirado como un igual y de anular su dignidad, destruyendo toda posibilidad de relaciones pares.

"Los conceptos de amigo, enemigo y combate reciben su sentido concreto por el hecho de que se relacionan especialmente con la posibilidad real de la muerte física y mantienen esa relación. La guerra proviene de la enemistad puesto que ésta es la negación esencial de otro ser”. (Ibid: 16). 
Esta forma de percibir la realidad de nuevo permea todos los espacios de la vida, convirtiéndose en un molde en cuyo interior todo tipo de conflicto adquiere la misma forma. Restringir la política al ámbito de lo macro impide el comprender que este aprendizaje se adquiere a través de los criterios sociales de lo ético, lo estético y lo moral, y de acciones repetidas que establecen los dualismos como parte de la realidad. No creemos en lo que vemos, vemos lo que creemos.

La necesidad de una autoridad suprema, -siempre arriba, dueña de la fuerza suficiente para imponer una sola forma de pensar y de vivir y capaz de infligir el miedo necesario para garantizar la obediencia- y el dualismo amigo-enemigo que, como casi todos los dualismos, tiende hacia la destrucción o el sometimiento del opuesto, son dos de los imaginarios que le dan forma al cuenco cultural hegemónico. Sin embargo, las rupturas de la confianza entre representantes y representados han dejado de ser fisuras para convertirse en abismos que impiden cada vez más el reencuentro y los sistemas políticos se sostienen más por la inercia de las normas, que no por la legitimidad necesaria para que sobrevivan. Es en medio de esta crisis que empiezan a aparecer otras formas de hacer y pensar la política, aún sin la suficiente visibilidad pero sí con la decisión de darle nuevos contenidos, que desdigan de las verdades que hasta hoy parecen haber sido incuestionables.

\section{Mirar con otros ojos, acudir a nuevas epistemologías}

Las interpretaciones y las percepciones sociales se realizan en el ámbito del cuenco mismo de la cultura. Las emergencias, las transformaciones, las líneas de fuga no figuran en los aprendizajes que se pretenden, explicando la ausencia de reflexiones y estudios sobre las experiencias históricas que las plantean. Los cambios que están ocurriendo suceden en medio de la incomprensión de una sociedad que no sabe renunciar a una manera de mirarsey de interpretar la realidad. Se hace necesario "leer con otros ojos”, acudir a nuevas perspectivas epistemológicas que nos permitan fugarnos de una mirada restringida al espacio cultural dominante. Éstas nos están ayudando a entender y aprehender la noviolencia, como construcción histórica inacabada y abierta a los aportes de nuevos protagonistas en cada vez más formas de hacer y pensar la realidad humana.

La genealogía plantea un giro que se aparta del objetivismo cartesiano, asumiendo formas multidimensionales del pensamiento, fundados en la diversidad y alejadas de las certezas y lógicas unívocas. (Useche, 2014: 30)

"En lo que atañe a la vida humana, desde la perspectiva genealógica, dejan de naturalizarse las instituciones, los conceptos, los valores, las regulaciones y se hace un esfuerzo por descifrar el espacio y el tiempo en el que emergen, marcados por las condiciones de existencia, por el clima cultural y por las relaciones axiológicas dominantes... Ello implica una actitud 
crítica frente a las interpretaciones, significados y valores que se erigen, inmutables y autónomos, frente al fluir de la vida”. (Ibid: 29).

Evidenciar que la realidad responde a los límites impuestos por el cuenco cultural, como lo hacen Hobbes y Schmitt, no logra dar cuenta ni explicar las transformaciones que están ocurriendo y que se condensan en el tiempo, cuando crece la evidencia de que la cultura se ha desconectado de su propósito de mantener y proteger la vida. Es entonces cuando ésta se torna también en un sistema abierto y creativo, que se expresa especialmente en los márgenes de la sociedad.

Juan Pablo Lederach llama a esta fuerza que presiona el cambio de la realidad cultural, la imaginación moral y la define como "la capacidad de dar a luz algo nuevo que por su mero nacimiento cambia nuestro mundo y la forma en la que observamos las cosas.”(Lederach, 2008: 54).

Castoriadis hace referencia a esta fuerza creativa llamándola autoalteración:

“La sociedad es siempre histórica en el sentido extenso, pero propio, del término. Ella atraviesa siempre un proceso de autoalteración, ella misma es un proceso de autoalteración. Este proceso puede ser, y casi siempre ha sido, suficientemente lento para ser perceptible. Se sabe que en nuestra pequeña provincia social histórica, ha sido, durante los últimos 4.000 años demasiado rápido y violento. La cuestión de (...) saber cuándo una sociedad deja de ser 'la misma' y se vuelve 'otra' es una cuestión histórica concreta a la cual la lógica habitual no puede dar respuesta”. (Castoriadis, 1998: 192).

Al ser definidos como seres culturales, cambiar supone también construir nuevas simbologías o releer y replantear el universo de las significaciones de las existentes. De alguna forma supone la construcción de nuevos mitos porque "cuando los hechos cambian y los mitos continúan siendo esencialmente los mismos, es decir, sus significaciones no se transforman, terminamos haciendo interpretaciones iguales de circunstancias históricas distintas”. (Martínez, 2014: 15).

La pregunta que nos surge es ¿cómo se producen estos cambios?, ¿qué formas de pensar nos permiten presentirlos, percibirlos, visibilizarlos? Las teorías del caos y de la complejidad nos dan algunas claves para ello.

El principio hologramático atañe a una propiedad de las organizaciones complejas, “en las que no solamente la parte está en el todo, sino en la que el todo está inscripto en la parte” (Morin, 2002:99).

Morin explica que cada punto del holograma es “acogido” por el conjunto del todo, así como cada parte incorpora la presencia de la totalidad, lo que nos permite tener imágenes completas a partir partes parciales 
del mismo. Este principio se formula con base en lo anterior: el todo está, de alguna manera, incluido en la parte que está incluida en el todo.

Con el fin de explicarlo, Morin se refiere a la genética: la totalidad del patrimonio hereditario se encuentra en cada una de las células de un organismo, así como cada individuo es una expresión de la sociedad en su totalidad. Y aunque cada célula tiene la información de todo el organismo, sólo se expresa en su actividad concreta, es decir, de alguna forma la mayoría de su información está constreñida por el todo. En las sociedades sucede lo mismo, cada individuo tiene la información de la totalidad, pero el todo sólo le permite que se exprese como individualidad en su entorno particular.

Sin embargo, dicho constreñimiento no es definitivo, ni logra inhibir del todo la expresión particular, dado que las organizaciones hologramáticas tienen las siguientes características: a) Las partes pueden ser singulares u originales al mismo tiempo que disponen de los caracteres generales y genéricos de la organización del todo. b) Las partes pueden estar dotadas de relativa autonomía. c) Pueden establecer comunicación entre sí y efectuar intercambios organizadores. d) Pueden ser eventualmente capaces de regenerar el todo. (Morin, 1994:113).

Este principio hologramático que plantea Morin se complementa con lo que en el espacio de la acción política se llaman la micropolítica y la macropolítica del poder. En palabras de Óscar Useche:

"La micropolítica asume que todos poseemos un poder interior, una fuerza primaria y activa que son la vida misma desplegándose. Esa fuerza originaria no está determinada por la búsqueda del acceso y control de los centros de poder, ni se propone convertirse en organización burocrática de la potencia humana, ni dominar la sociedad desde un lugar jerárquico". (Useche, 2014: 33)

La imagen del tejido nos puede ayudar a comprender: El tejido está conformado por una repetición permanente del mismo ejercicio y cada nudo cumple con su misión de cara al conjunto; sin embargo, basta con que uno de esos pequeños nudos cambie el rol definido de intermediación entre el anterior y el siguiente para que se inicie una transformación de tejido en su conjunto. Hebras sueltas que, jaladas incluso por el azar, pueden terminar desdibujando ese conjunto que parecía armónico. Es en el espacio de la parte, desde su propia singularidad y autonomía, donde se puede ejercer el ejercicio de la micropolítica, estableciendo comunicaciones creativas con su entorno, que pueden terminar por regenerar el todo.

En la teoría del caos, a este poder interior, fuerza primaria y activa, que potencia el espacio de la micropolítica, sus autores le llaman el poder de la influencia sutil:

"La influencia sutil (...) en su sentido positivo es vital para mantenerlos sistemas abiertos, renovados y vibrantes. (...) Ese es el poder real de la 
impotencia. En el acto de darnos cuenta auténticamente de la realidad del momento reside nuestra habilidad para influir, si bien con humildad, incluso en los sistemas más rígidos, construidos en función del automatismo y de las frases vacías (...) Pero la teoría del caos nos recuerda que el mundo real fluye permanentemente y cualquier contexto puede cambiar y, de hecho, cambiará. Mañana podemos descubrir un modo de hacer las cosas que hoy nos resulta inconcebible”. (Briggs, Peat, 1999: 56 y ss).

Por otra parte, el todo de Morin podría ser equiparado a lo que se nombra como la macropolítica del poder que “obedece a la concepción dominante en la política moderna... alrededor de un poder que homogeniza, indiferencia, clasifica y ordena”(Useche, 2014: 34). Los aportes reflexivos de Hobbes y Schmitt están referidos a este espacio de la política. Ayudan a entender sus lógicas, pero se muestran incapaces de comprender y admitir que existen otros espacios y otras lógicas del poder.

No se trata de construir nuevos dualismos entre micro y macropolítica, entre el todo y la parte. Es la relación permanente entre el nudo y el tejido la que los deconstruye. El aporte más importante de estas reflexiones es que nos permite concebir el poder en otras lógicas, le da un protagonismo a los llamados poderes de periferia, que en los tratados tradicionales de la política sólo existen para ser dominados, conducidos y que contempla sólo pequeños espacios de autonomía (el supuesto voto individual) para ser de nuevo capturados por la política de la representación. En esta percepción sólo les queda la homogenización como alternativa, pues la autonomía es satanizada por la relación excluyente del amigoenemigo.

"La creatividad no es solo lo que se manifiesta en los campos creativos reconocidos tradicionalmente; es también lo que sucede en nuestros pequeños o grandes momentos de empatía y transformación, los momentos en los que entramos en contacto con nuestra auténtica experiencia individual, y por lo tanto universal, de la verdad. El psicólogo británico N. K. Humphrey sostiene que el mayor uso que hacemos los hombre del intelecto creativo no se produce en el arte o en la ciencia, sino en los actos espontáneos del día a día que permiten mantener la cohesión social”. (Briggs, Peat, 1999: 38).

Estas nuevas formas de leer y entender la realidad social se están encontrando de forma innovadora con las experiencias históricas de la noviolencia. Ellas también han sido profundamente creativas, han revalorado el poder de la gente en los espacios de la micropolítica para, desde allí, incidir en profundas transformaciones de los ámbitos macro; han disuelto las lecturas dualistas de la realidad, expresadas, entre otras formas, en la relación amigo-enemigo. El desmonte del Apartheid en Sudáfrica aporta elementos a los nuevos caminos que la humanidad se atreve a transitar. 


\section{La experiencia de Mandela y su gente enriquecen la construcción histórica de la noviolencia}

Las palabras, entendidas como signos que expresan una simbología cultural, solo pueden ser comprendidas si existe una construcción histórica y social que las acoge, las comprende y las convierte en acciones. El ámbito histórico de la cultura es la que les da contenidos. ¿Cómo se escapa, entonces, la historia de no ser una cascada de repeticiones? Solo la emergencia, el acto creativo, el acontecimiento, la natalidad, presentes en la misma cultura, puede dar sentido a una construcción social como fuga del acto repetitivo. No es sólo la expresión individual quien lo provoca, debe existir una necesidad creada en lo más profundo del espíritu humano para ser comprendida y asumida, para dar un paso adelante en este proceso de evolución social.

No es una eventualidad que la propuesta de la noviolencia surja en medio de las profundas conmociones que provocaron en la humanidad los hechos de guerra con los que se inició y desarrolló el siglo XX. Es en medio de la muerte y el dolor humano de la primera guerra mundial, de la revolución rusa y la mexicana, por nombrar sólo algunas, que Gandhi aprende otra forma de ejercer la política, asumiendo en sus prácticas el significado profundo de la palabra ahimsa: no producir daño ni sufrimiento. Desde allí, se trataba de aprender. Y es casualmente en Sudáfrica, la patria de Mandela, donde inicia este aprendizaje que no terminó nunca. La indignación personal que le produjo ser arrojado del tren en que viajaba, conectó con indignaciones similares en sus amigos y conocidos. Fue una experiencia profundamente micropolítica que recogió sentires colectivos y se amplió hasta ser millones. Fue la expresión del poder de la fragilidad amparado en una verdad simple y asumida: la dignidad humana, como hemos explicado anteriormente.

"La fortaleza del frágil está, como lo indica la Satyagraha, en el poder de la verdad que defiende, poder que surge de su capacidad de suscitar un trabajo colectivo... El cambio cultural que plantea Gandhi no radica en proponer una verdad distinta alrededor de la cual convocar a la gente y a la que hay que adherirse en virtud de su nivel de bondad e importancia. Ello significaría seguir creyendo que el problema se encuentra en la definición de una verdad externa, objetiva, universal, incuestionable y única. El cambio y su fortaleza radican en la forma como la verdad se construye, en el proceso intersubjetivo de elaboración permanente de la misma, siendo ella, entonces, el resultado de un proceso social en una situación histórica determinada. Ello no supone caer en un relativismo absoluto porque, para Gandhi, la verdad existe, es una realidad ontológica, pero los seres humanos sólo podemos acercarnos a ella desde nuestras propias percepciones. En consecuencia, lo que es relativo es nuestro acercamiento, razón por la cual nadie puede considerarse dueño de la verdad ni, por lo tanto, legitimar ningún tipo de violencia para obligar a su adhesión”. (Martínez, 2014: 188) 
En la maraña de las múltiples guerras y violencias del siglo pasado no es fácil percibir las emergencias y natalidades en el proceder humano. Siempre es importante recordar la lucha por los Derechos Civiles en Estados Unidos, inspiradores de otras gestas contra el racismo, los movimientos feministas, ecologistas y pacifistas que no han planteado sus esfuerzos colectivos con la intermediación de la violencia. Es una manera de hacer, que se expresa en múltiples latitudes, sin que logremos entender con la racionalidad hegemónica, ni los cómo ni los por qué de sus coincidencias.

Quiero dar cuenta de una experiencia vivida que habla de las emergencias a las que quiero referirme. Siempre me gusta comentar lo que voy pensando con la gente que la vida cruza en mi camino. Un taxista de la ciudad de Bogotá me decía al respecto: Sabe que usted tiene razón? Tengo un tío que posee una parcela en los llanos orientales. Levantó una cerca para fijar sus límites y, especialmente, para proteger sus sembrados del ganado que tenía su vecino. Sin embargo, éste se empeñaba en romper dicha cerca y los animales arruinaban su trabajo. Con paciencia, mi tío reparaba la cerca, para encontrar al día siguiente la misma situación. Un día le dije: deje que yo le “soluciono” este problema, sugiriendo que sólo el uso de la fuerza podía darle salida. Me respondió: usted no se meta mijo. Un día estaba trabajando en su parcela, reparando los daños en su cultivo, cuando pasó el vecino. Mi tío cortó un racimo de plátanos y se lo entregó, diciéndole: tome vecino, para que se haga una sopa. Su sorpresa fue tanta que a partir de ese día nunca más volvió a romper la cerca y hoy son los mejores amigos. ¿Qué está sucediendo en nuestra realidad social para que Mandela y un simple campesino colombiano estén buscando soluciones creativas a sus conflictos, eximiéndose de lo que culturalmente se espera de ellos? ¿O es que siempre ha sucedido $\mathrm{y}$, simplemente, hemos empezado a verlo hasta ahora? Mis comentarios suscitaron en el taxista otra visión de una anécdota de su vida y la compartió conmigo con una nueva perspectiva.

Este relato guarda relación con lo planteado por Gandhi a través de la Satyagraha. Se trata de construir una fuerza en otras lógicas que no pretenden el triunfo a través de la dominación, sino la transformación de sus protagonistas y de la relación existente. Es una fuerza moral que deshace la relación amigo-enemigo y que ocurre en los espacios de la periferia, allí donde la vida se expresa y se escapa a los condicionamientos hegemónicos.

Pero el propósito de este ensayo está en observar con más detalle la lucha de la Sudáfrica negra contra el apartheid, -encabezada por el Congreso Nacional Africano,con el liderazgo de Nelson Mandela-, y algunos de sus aportes a esta construcción de humanidad que llamamos la noviolencia. Es un aprendizaje histórico y en proceso. Con ello quiero decir que es profundamente inductivo y de carácter colectivo. La primera etapa estuvo muy inspirada en la propuesta de la noviolencia, a partir de los aportes de Gandhi a la lucha social. Sin embargo, los hechos de Sharpeville (1960), en los que las fuerzas de seguridad del apartheid dispararon indiscriminadamente contra la población desarmada, que había decidido quemar los documentos que les restringía la libre circulación por el territo- 
rio, dieron un giro a los métodos de lucha. Mandela es encargado por el CNA para organizar la estrategia armada contra el gobierno de Sudáfrica, por lo que es encarcelado y condenado a cadena perpetua.

"En mayo y junio de 1961, era imposible negar que nuestro intento de alcanzar un estado no racista por medio de la noviolencia no había dado fruto, y que nuestros simpatizantes empezaban a perder la confianza en nuestra política y comenzaban a plantearse preocupantes proyectos de terrorismo" (Mandela, 2010: 377).

Se había hecho una opción consciente por transformar los métodos de lucha, pero aquellos elementos de la noviolencia que los trascienden, necesitaban un proceso más lento y largo. Es importante resaltar que la dupla violencia-noviolencia no es un nuevo dualismo conformado por polos químicamente puros. Sería caer de nuevo en la cultura que se quiere transformar. Es un camino, un tránsitoque pretende arrinconar la tentación de la violencia socialmente aprendida, pero entendiendo que sus legitimaciones sociales hacen parte de una forma de pensar que nos atraviesa. Adquiere aquí sentido una de las características de las organizaciones hologramáticas que plantea Morin: las partes pueden ser singulares u originales, al mismo tiempo que disponen de los caracteres generales y genéricos de la organización del todo. Los seres humanos, y las organizaciones que creamos, estamos imbuidos al tiempo por las emergencias creativas y la cultura en la que hemos sido socializados. En palabras de Mario López:

"La noviolencia es un comportamiento mental, una predisposición, un estilo de vida, que dota de compromiso y coraje a aquellos que, deliberadamente, eligen una resistencia activa que se funda en el principio de actuar, siempre, en manera tal que el resultado de la propia acción sea el disminuir la violencia. No es ciego fanatismo o dogmatismo... es compromiso vital para buscar soluciones que reduzcan el sufrimiento humano creado por todas las formas de expresión de la violencia.” (López, 2012: 45).

También es importante entender que Mandela es la expresión de una línea de fuga colectiva. Sin ello no habría podido existir la concurrencia armónica necesaria para que hiciera eco en el conjunto social. No es posible seducir sin ello.Tal vez se trata de entender las palabras de Carlin cuando dice que "para cautivar, un drama necesita que el espectador tenga una condición humana común con los protagonistas" (Carlin, 2009: 86).Mandela y su gente no son una excepción iluminada de la humanidad, sino la expresión de una realidad histórica. Particularizar una situación tiene la intención de hacerla única e inimitable y se torna una manera de demostrar que nada ha cambiado en esencia. Creer que la genialidad de un ser humano fue la gestora de una transformación es desconocer que somos expresión de la sociedad que nos rodea en sus fugas y repeticiones. Mandela era muy consciente de que su sueño había sido compartido y sostenido por miles de hombres y mujeres, que supieron mantenerlodurante sus largos años de cárcel. 
En este sentido, cabe resaltar que la lucha de Sudáfrica contra el apartheid aporta el tema de la importancia de los liderazgos colectivos, como una característica privilegiada de la noviolencia. Mandela, con el régimen de aislamiento al que estuvo sometido, no hubiera podido sostener el liderazgo único que en ocasiones se le atribuye. Su aporte y el de sus amigos presos, fue más en el campo de lo simbólico, por demás fundamental, pero no el de un liderazgo supeditador y jerarquizado, como se entiende en la cultura hegemónica. Contribuciones tan importantes como el de Steve Biko, que trabajó en la recomposición de la dignidad de su gente, como condición sine qua non para la conciencia del propio poder, no parecen ser conocidos por Mandela. De hecho ni siquiera es nombrado en su larga autobiografía y es seguro que éste es sólo un ejemplo de muchas experiencias de resistencia noviolenta, como los boicots económicos. Ejercer el liderazgo colectivo parte de creer que todo aporte es el despliegue creativo del propio poder, valorando los espacios de la micropolítica, desde la perspectiva del poder de la influencia sutil. Ya Gandhi hacía referencia a ello al decir "Casi todo lo que realice será insignificante, pero es muy importante que lo haga”.Mandela lo reconocía en su primer discurso al salir de la cárcel:

"Vuestro incansable y heroico sacrificio ha hecho posible que hoy me encuentre aquí. Por ello pongo en vuestra manos los días de vida que puedan quedarme... Hablaba de corazón. Antes de nada, quería expresar ante el pueblo que yo no era ningún mesías, sino un hombre corriente que se había convertido en un líder por circunstancias extraordinarias”. (Mandela, 2010:586).

Otro aporte que quiero resaltar es la importancia de los espacios de la micropolítica para transformar la relación amigo-enemigo en las relaciones macropolíticas. Estas, por su propia especificidad, se conciben como un ámbito de confrontación en el que la relación amigo-enemigo, la desconfianza y el miedo al otro-distinto se reproducen casi que inconscientemente, impidiendo transformar de forma definitiva las relaciones de poder, la construcción social de la verdad, como la planteaba Gandhi, y el develar que el opositor no es solamente los planteamientos ideológicos que defiende, o sus posturas políticas. Es más, este espacio evita todo tipo de acercamiento distinto. No en vano a los soldados de todos los ejércitos se les educa para no mirar a los ojos de sus enemigos. El miedo y el odio al otro, impiden percibir la humanidad que hay detrás del disfraz ideológico que viste el opositor,así como también que ese otro se mire a sí mismo más allá de su uniforme, para descubrir su propia y esencial dimensión humana.

Vale la pena repasar algunos eventos de la vida de Mandela en la cárcel, del ámbito de la micropolítica, que posiblemente transformaron de forma importante sus percepciones de la misma lucha macro.

Ya antes de ser enviado a la cárcel, Mandela contemplaba la posibilidad de una sociedad de convivencia conjunta sin exclusiones. Así lo dejó claro en su defensa antes de ser condenado: 
"He dedicado toda mi vida a la lucha del pueblo africano. He combatido la dominación blanca y he combatido la dominación negra. He acariciado el ideal de una sociedad democrática y libre, en la que todas las personas convivan juntas en armonía y con igualdad de oportunidades. Es un ideal por el que espero vivir y que aspiro a alcanzar. Pero, si es necesario, es un ideal por el que estoy dispuesto a morir”. (Idem: 381).

Lo micro y lo macro se afectan o pueden afectarse mutuamente. Por ello cambiar la forma de percibir al otro, transforma también las acciones que se derivan de ello, abriendo las posibilidades de manejo de la sociedad y los conflictos, sin acudir a la guerra y a la desaparición del poder del otro.

Mandela aprendió a fortalecerse con las experiencias personales más simples; en su autobiografía aparecen recurrentes testimonios en este sentido; ello plantea, de alguna forma, que para hacer política en lógica de noviolencia es importante desarrollar la capacidad de una sensibilidad aferrada a lo simple. Como señala Lederach, "la creatividad se mueve más allá de lo existente hacia algo nuevo e inesperado, surgiendo a partir de y hablando a lo cotidiano” (Lederach, 2008: 70).Así, el propio Mandela confiesa:

"Un jardín era una de las pocas cosas que uno podía controlar estando en la cárcel. Plantar una semilla, verla crecer, cuidar la planta y después recoger sus frutos era una satisfacción sencilla pero profunda. La sensación de ser el custodio de aquella pequeña superficie de tierra tenía un cierto regusto a libertad”. (Mandela, 2010: 506)... “Algunas mañanas salía a pasear por el patio y todos los seres vivientes que allí había, las gaviotas y las lavanderas, los pequeños arbolitos e incluso las escasas hojas de hierba parecían sonreír y brillar bajo el sol. En momentos así era cuando percibía que incluso en aquel remoto y encerrado rincón del mundo había belleza, cuando me sentía seguro de que algún día mi pueblo y yo seríamos libres”. (Idem: 523).

Aprendió a encontrarle significados a aquellos actos que se consideran del ámbito de lo privado y a relacionarlos con sus opciones políticas. Es bastante normal que afinquemos nuestros deseos de cambio y transformación en aquellos espacios a los que normalmente no tenemos acceso, desconociendo que la esperanza se fortalece pudiendo donde se puede, es decir, desplegando el pequeño poder de cada cual en los lugares donde ese poder tiene capacidad real de transformación. Gandhi imaginó sus grandes gestas en el contacto sencillo con la gente con la que convivía, sabiendo leer e interpretar sus más profundos sentires:

"Sujetar a un bebé recién nacido, tan vulnerable y suave con mis manos encallecidas, manos que durante demasiado tiempo solamente habían conocido el contacto de picos y palas, fue un gozo inenarrable. No creo que ningún hombre se haya sentido más feliz por sostener a un bebé de lo que me sentí yo aquel día... Era costumbre que el abuelo eligiera el nombre. Yo había decidido Zaziwe, que significa esperanza. El nombre tenía 
para mí un significado especial ya que durante todos los años que llevaba en la cárcel, la esperanza jamás me había abandonado. Estaba convencido de que aquella niña sería parte de una nueva generación de sudafricanos para los que el apartheid no sería más que un vago recuerdo”. (Idem: 512).

En concordancia con lo anterior, descubrió la importancia de valorar aquellas experiencias que conectaban las pequeñas luchas con el objetivo final, estableciendo esa conexión de mutua afectación entre lo micro y lo macro.

“La campaña para mejorar las condiciones de vida en la prisión formaba parte de nuestra lucha contra el apartheid. Es ese sentido librábamos la misma batalla. Nos enfrentábamos a la injusticia allí donde la encontrábamos, sin importar sus proporciones, y esto nos ayudaba a preservar nuestra humanidad”. (Idem: 421).

Mandela no sólo desconcertó a sus opositores con su forma de relacionarse con ellos, sino que también se permitió dejarse sorprender por aquellas dimensiones de humanidad que se asomaban, tal vez tímidamente, en las acciones de sus contradictores. En concreto, reconoce en su autobiografía la sorpresa que le produjo uno de sus más implacables carceleros, el coronel Badenhorst:

"Me dijo que iba a abandonar la isla y añadió: Tan solo quiero desearles buena suerte. No sé si se me notó mi cara de asombro, pero me quedé pasmado. Había hablado como un ser humano y había mostrado una faceta de su personalidad que jamás habíamos tenido ocasión de apreciar antes... Fue un recordatorio útil de que todos los hombres, incluso los más fríos en apariencia, tienen algo de decencia, y que si se consigue llegar a su corazón son capaces de cambiar. Badenhorst no era un malvado. Su falta de humanidad le había sido impuesta por un sistema inhumano. Se comportaba como un bruto porque esa era la clase de comportamiento que se recompensaba”. (Idem: 478, 479).

También reconoció haberse sorprendido con otro tipo de relaciones que no hubiera esperado de las personas que acompañaron su cautiverio. Parecemos aferrados a relacionarnos a través de los estereotipos que han formado nuestra percepción del otro; y la macropolítica, aferrada a la relación amigo-enemigo, no permite develar aquello que es capaz de crear otro tipo de vínculos a través de los cuales se pueden encontrar líneas de fuga a los dualismos excluyentes.

“Swart nos preparó una comida de despedida y le di las gracias, no sólo por las comidas que me había preparado a lo largo de los últimos años, sino por su compañía. También el suboficial James Gregory estaba en la casa y le abracé calurosamente... se había creado entre nosotros un fuerte vínculo tácito y echaría de menos su tranquilizadora presencia. Los hombres como los funcionarios Swart, Gregory y Brand reforzaban mi convicción de que incluso quienes me habían mantenido entre rejas durante veintisiete años y medio eran esencialmente humanos”. (Idem: 582). 
La propuesta de la noviolencia aprende de estas experiencias a entrar en un campo distinto que valora gestos no esperados. Esta relación de afectación mutua entre lo micro y lo macro potencia ambos ámbitos: Valora lo micro y transforma la percepción de lo macro.

"Lo que me sorprendió fue el número de familias blancas que salieron a la carretera a vernos pasar...Algunos de ellos incluso levantaron el puño derecho, haciendo lo que se había convertido en el saludo del CNA... Aquello me dejó pasmado... En un momento dado hice parar el coche y me apeé de él para saludar y dar gracias a una familia blanca y decirle hasta qué punto me sentía conmovido por su apoyo”. (Idem: 584).

Esta capacidad de asombrodesarrolló al tiempo una impronta de su fuerza comunicativa: ser capaz de sorprender. A esta característica la podríamos llamar el poder del desconcierto. Cuando se responde de una forma no esperada, éste reduce nuestras alertas de protección y abre caminos no transitados. Así sucedió con muchas de las personas que trabajaban en las oficinas de la presidencia, cuando Mandela llegó a ella. Esperaban ser despedidos y él les dijo que necesitaba de sus conocimientos para cumplir mejor con su labor.

"Mandela se mostraba todo caballerosidad con aquella mujer, que unos días más tarde le devolvió el cumplido declarando a la prensa local que nunca había recibido de ninguno de los paisanos afrikáners para los que había trabajado una muestra de respeto y amabilidad comparable a la de Mandela. ... Le había concedido el regalo del perdón, pero según su forma de ver las cosas, ella había sido lo bastante generosa para aceptarlo”. (Carlin, 2013: 24).

Tratar distinto a sus opositores se volvió una forma de actuar:Y esto, que parece más del ámbito de las relaciones interpersonales, en lógica hologramática tiene efectos no esperados en los espacios de la macropolítica.

“También me preguntaron por el miedo que sentían los blancos. Sabía que todo el mundo esperaba que albergara resentimiento hacia ellos, pero no era así. Durante mi estancia en la cárcel mi ira hacia los blancos había disminuido; por el contario, había aumentado mi odio hacia el sistema. Quería que toda Sudáfrica viera que amaba a mis enemigos, aunque aborrecía el sistema que nos había enfrentado... Todo hombre o mujer que abandonara el apartheid sería bienvenido a nuestra lucha en pro de una Sudáfrica democrática y no racista. Debíamos hacer todo lo que estuviera en nuestras manos para convencer a nuestros compatriotas blancos de que la nueva Sudáfrica sería un lugar mejor para todos”. (Mandela, 2010: 588, 589).

Esta manera de proceder fue fundamental en uno de los momentos más difíciles, cuando todo parecía indicar que Sudáfrica estaba condenada a una guerra interna de proporciones inimaginables. El general Viljoen, con un importante reconocimiento por parte de los Afrikáner más radicales, el Volksfront, había aceptado liderar la resistencia armada a la posibilidad de 
una Sudáfrica en manos de la mayoría negra. El mismo general reconocería después detalles aparentemente intrascendentes que resultaron fundamentales para cambiar su decisión.

Mandela se dirigió a él en perfecto Afrikáans. En la cárcel había tomado la decisión de aprender la lengua de su opositor y de conocer y comprender su forma de pensar. Al tiempo que evidenció el profundo daño que el pueblo Afrikáner le había infligido a él y a su gente, también le manifestó el gran respeto que le inspiraba, el derecho que tenían a compartir la tierra sudafricana y cómo el miedo y la culpa eran la principal motivación de sus acciones. Después de varios encuentros, Viljoen tomó la decisión de ordenar a sus partidarios suspender la lucha armada. (Carlin, 2013).

Esto guarda relación con aquellas palabras de Gandhi "los británicos no son nuestros enemigos, son nuestros amigos y necesitan liberarse tanto como nosotros”.(Martínez, 2014: 203).En palabras de Bill Clinton: "Mandela nos incita a todos a ser mejores seres humanos". (Carlin, 2013: 113).

Mucha gente piensa que este acercamiento a comprender las razones del opositor, termina por justificar sus acciones y por ablandar a los que luchan por un mundo más justo y equitativo. Se cree que el odio y el rencor son los acicates fundamentales del empeño transformador. Mandela también contradijo estos temores, pues siempre expresó con decisión las razones profundas de sus luchas colectivas.En respuesta al ofrecimiento de dejarlo libre si renunciaba a la violencia, planteó:

“Me sorprenden las condiciones que el gobierno desea imponerme. No soy un hombre violento... Sólo cuando no nos quedaron más medios de resistencia tuvimos que recurrir a la lucha armada... Que renuncie él a la violencia. Que diga públicamente que desmantelará el sistema del apartheid. Que levante la prohibición que pesa sobre la organización del pueblo, el CNA... Sólo los hombres libres pueden negociar. Los prisioneros no pueden formalizar contratos... No puedo, ni pienso hacer promesas en un momento que vosotros, el pueblo, y yo, no somos libres. No se puede separar vuestra libertad de la mía”. (Mandela, 2010: 540, 541).

Y ante la solicitud de DeKlerk de solicitar el levantamiento de las sanciones económicas sobre Sudáfrica, manifestó:

"Yo era consciente de que la CE y EEUU se mostraban inclinados a relajar las sanciones sobre la base de las reformas introducidas por de Klerk. Le expliqué a éste que no podíamos decirles a nuestros defensores que relajaran las sanciones hasta que hubiera desmantelado por completo el sistema del apartheid y se hubiera instaurado un gobierno de transición”. (Idem: 602).

La valoración de la micropolítica como parte importante de la noviolencia no supone ni significa despreciar ni desconocer la importancia 
de las luchas macropolíticas. Como nos cuesta trabajo prescindir de las percepciones dualistas, es fácil que se concluya que el énfasis en lo primero suponga el desconocimiento de lo segundo. Lo que nos enseña la experiencia de Mandela y su gente es la profunda relación entre ambas dimensiones.

Las palabras de John Carlin resumen mejor que nadie algunas de las características de Mandela que permitieron que el régimen del apartheid, pensado e instaurado con pretensiones de perennidad, se desmoronara:

"Fueron su integridad y su coraje, sumados a su encanto y su poder de persuasión, los que convencieron a sus enemigos para que cedieran el poder voluntariamente, convencidos de que se trataba de un líder en quien podían confiar para evitar el camino de la venganza que sus conciencias culpables tanto temían”. (Carlin, 2013: 26).

\section{A modo de conclusión}

He intentado hacer énfasis en aprendizajes que, reconozco, se salen de las reflexiones que se consideran propias de la política. Las transformaciones que necesitamos como humanidad pasan por enseñar a conocer el mundo con otros ojos, nuevas epistemes que visibilicen, expliquen y legitimen la realización de políticas alternativas propias del ámbito de la noviolencia.

En lugar de ello, seguimos empecinados en repetir fórmulas que han demostrado su incapacidad para viabilizar soluciones reales. Las transformaciones conseguidas a través de la noviolencia permanecen en el ámbito de lo impracticable, porque creemos que ser realistas consiste en intentar imprimir más terror en nuestros enemigos del que ellos son capaces de infligir. La fórmula se repite en Palestina, de uno y otro lado, en Europa, en Irak, en México, en Colombia, en Afganistán, en Siria... En lugar de tumbar los muros que nos separan, físicos e ideológicos, los levantamos más altos e infranqueables.

Al funeral de Mandela asistieron muchos de los que hoy siguen decretando la guerra como solución. Es posible que su sentimiento de admiración sea genuino, pero no hasta el punto de considerar que sean imitables sus formas de proceder en el campo de la política. Los estudios de la Ciencia Política siguen prefiriendo las reflexiones de Hobbes y Schmitt que las de Gandhi o Mandela, por considerarlos, como ya se dijo, exotismos históricos o peligrosa ingenuidad.

La bella fábula de la película del director Húngaro Kornel Mundruczó, White $\mathrm{God}^{3}$, nos puede invitar a buscar los lenguajes que pacifiquen el alma humana, que reconcilien esta humanidad empeñada en repetir el mismo esquema cultural que sólo ha logrado reproducir la muerte y el dolor. De nuevo Mandela, nos recuerda que exacerbar el dolor y el miedo es un círculo vicioso de destrucción. 
Aprendemos a juzgar a las personas por los roles que desempeñan, sin descubrir que detrás se refugia una subjetividad a cuya dimensión de humanidad se puede apelar. Ser capaz de suscitar lo mejor de cada cual es un llamamiento a la parte más sabia de sus naturalezas. La noviolencia, como experiencia histórica de transformación cultural, sigue aprendiendo a construir formas de suscitar esa dimensión de humanidad que, a pesar de no tener reconocimiento en el ámbito de la cultura hegemónica, sigue manifestándose aunque aún no tengamos los ojos que se necesitan para verla y potenciarla. 


\section{Notas}

${ }^{1}$ En el diccionario, “atávico" hace referencia a la tendencia a imitar y mantener costumbres propias de épocas pasadas; se aplica a la cualidad hereditaria que procede de antepasados lejanos, es un aprendizaje no consciente, recurrente, patriarcal.

${ }^{2}$ A modo de ejemplo. En la constitución colombiana, redactada y expedida en 1991, la soberanía pasó de la Nación al Pueblo. Sin embargo, las prácticas siguen siendo las mismas, ya que el Estado, y el gobierno que lo representa, considera que está por encima de cualquier decisión popular. En 2013, el municipio de Piedras, en el departamento de Tolima en Colombia, dijo NO a la utilización de su territorio para actividades mineras extractivistas. La votación del NO fue contundente: 2.971 votos (99,2\%). Por el Sí sólo votaron 24 personas. Dos votos nulos y 10 en blanco. Es decir, el 59\% de la población habilitada, cifra muy superior al umbral de 1.700 sufragios, votó en contra de la megaminería y a favor de la vocación productiva agrícola de este municipio arrocero. Tanto el Ministro de Minas y Energía, Federico Renjifo, como el Ministro de Medio Ambiente, Juan Gabriel Uribe, señalaron que la política minera se elabora desde el gobierno. En Mayo se expidió un decreto según el cual es el gobierno el que tiene la última palabra en cuanto a la explotación minera o extractiva, decreto que está en contradicción con las reglamentaciones constitucionales en torno al mecanismo de la consulta popular. El Ministro Renjifo afirmó que las comunidades pueden opinar, pero que “el Estado es dueño del subsuelo" (Gutiérrez, 2013). Es decir, está fuera de discusión que quien detenta el poder está por encima de quien lo elige e, incluso, de la ley; y de alguna forma, una buena parte de la población asume como un acto de rebeldía irracional manifestaciones como la protagonizada por los habitantes de este pequeño municipio colombiano.

${ }^{3}$ El director húngaro construye una fábula en la que los perros, los animales más cercanos a los seres humanos, desatan una rebelión que construye su justificación en el abandono, la violencia y la discriminación. Nadie se pregunta los por qué de este inesperado comportamiento, sólo son terroristas que hay que eliminar. Al final es una niña la que consigue entender que lo que se necesita es un lenguaje común que reconecte las esencias, que deconstruya las superioridades racistas y permita desmontar el círculo vicioso de las violencias. 
Polis, Revista Latinoamericana, Volumen 15, $N^{\circ}$ 43, 2016

\section{Bibliografía}

Briggs, John \& Peat,David (1999), Las siete leyes del caos, las ventajas de una vida caótica, Editorial Grijalbo, Barcelona.

Carlin, John, (2009), El factor humano, Editorial Seix Barral, Barcelona.

Ídem, (2013), La sonrisa de Mandela, Penguin Random House Grupo Editorial, Bogotá.

Castoriadis, Cornelius (1998), Los dominios del hombre, Gedisa, Barcelona.

Gutiérrez, José Antonio (2013), , en La Pluma, 2 de agosto de 2013, fecha de consulta 25-01-2016, disponible en

Hobbes, Thomas (1651), Leviatán. Biblioteca del Político. www.uruguaypiensa.org.uy/imgnoticias/749.pdf

Lederach, Juan Pablo (2008), La Imaginación Moral - El arte y el alma de construir la paz, Editorial Norma, Bogotá.

López, Mario, (2012), Noviolencia - Teoría, acción política y experiencias, Educatori, Granada.

Mandela, Nelson (2010), El largo camino hacia la libertad, Editora Aguilar, Altea, Taurus, Alfaguara SA, Bogotá.

Martínez, Carlos (2014), De nuevo la vida - El poder de la noviolencia y las transformaciones culturales. Editorial Trillas, Bogotá.

Morin, Edgar(1994), El Método III. El conocimiento del conocimiento, Cátedra, Madrid.

Ídem (2002), La cabeza bien puesta, Nueva Visión, Buenos Aires.

Schmitt, Carl (1932), El concepto de lo político, Traducido de la edición de 1963 por Dénes Martos, http://webcache.googleusercontent.com/ search?q=cache:gV5FeA8oyuwJ:campusmoodle.proed.unc.edu.ar/ pluginfile.php/23308/mod_folder/content/0/Schmitt_Carl__El_Concepto_de_lo_Politico.pdf\%3Fforcedownload\%3D1+\&cd=2\&hl=es\&ct=clnk\&gl=co

Useche, Óscar (2014), Micropolítica de las resistencias sociales noviolentas - El acontecimiento de las resistencias como apertura de nuevos territorios existenciales. Tesis doctoral, Universidad de Granada. Granada. 